\title{
Intensified hemodialysis for complicated pregnancy in a primigravida with advanced maternal age: a case report with literature review focusing on appropriate hemodialysis management during pregnancy
}

Hiroyuki Arai ${ }^{1}$, Keita P. Mori ${ }^{1,2}$, Hideki Yokoi ${ }^{1 *}$ (D), Ken Mizuta ${ }^{1,3}$, Jumpei Ogura ${ }^{4,5}$, Ko Suginami $^{5,6}$, Tomomi Endo $^{7}$, Yoshihiro Ikeda ${ }^{8}$, Takeshi Matsubara', Tatsuo Tsukamoto ${ }^{7}$ and Motoko Yanagita ${ }^{1}$

\begin{abstract}
Background: Pregnancy in dialysis patients is rare but challenging both for nephrologists and obstetricians. Although intensified hemodialysis is effective to achieve favorable clinical outcomes in this clinical setting, the evidence concerning reliable parameters for the optimal dialysis prescription is scarce. Herein, we report a case of a primigravida with advanced maternal age who underwent a normal spontaneous vaginal delivery at full term managed by intensified hemodialysis, and discuss reliable indicators of the appropriate dialysis prescription.

Case presentation: A 39-year-old primigravida with end-stage renal disease was referred to our department for hemodialysis management during pregnancy. She had a history of multiple gynecologic disorders, including cervical dysplasia, right tubal ectopic pregnancy and spontaneous abortion; consequently, she conceived through in vitro fertilization and embryo transfer. After pregnancy was confirmed, an intensified hemodialysis schedule with weekly duration of 36 hours was employed to prevent volume overload and the accumulation of hyperosmotic substances. Utilizing maternal blood pressure, plasma atrial natriuretic peptide levels and fetal development as indicators of volume status, we incremented her dry weight by 300-400 g per week in the first and second trimester and 100-200 g per week in the third trimester, respectively. Serum urea nitrogen levels were persistently maintained below $50 \mathrm{mg} / \mathrm{dL}$. Throughout pregnancy, fetal growth and development were within normal limits. At 38 weeks and 3 days of gestation, she delivered a healthy child vaginally without complications. To date, the child's development has been normal, both physically and mentally.

(Continued on next page)
\end{abstract}

\footnotetext{
* Correspondence: yokoih@kuhp.kyoto-u.ac.jp

'Department of Nephrology, Graduate School of Medicine, Kyoto University,

54 Shogoin Kawahara-cho, Sakyo-ku, Kyoto 606-8507, Japan

Full list of author information is available at the end of the article
}

(c) The Author(s). 2020 Open Access This article is licensed under a Creative Commons Attribution 4.0 International License, which permits use, sharing, adaptation, distribution and reproduction in any medium or format, as long as you give appropriate credit to the original author(s) and the source, provide a link to the Creative Commons licence, and indicate if changes were made. The images or other third party material in this article are included in the article's Creative Commons licence, unless indicated otherwise in a credit line to the material. If material is not included in the article's Creative Commons licence and your intended use is not permitted by statutory regulation or exceeds the permitted use, you will need to obtain permission directly from the copyright holder. To view a copy of this licence, visit http://creativecommons.org/licenses/by/4.0/ The Creative Commons Public Domain Dedication waiver (http://creativecommons.org/publicdomain/zero/1.0/) applies to the data made available in this article, unless otherwise stated in a credit line to the data. 


\begin{abstract}
(Continued from previous page)
Conclusions: Pregnancy in dialysis patients with advanced age that leads to a normal childbirth is exceptionally rare. Our case is the hemodialysis patient with the most advanced age who achieves a normal spontaneous vaginal delivery at full term. Considering that cardiovascular system and endogenous metabolism dynamically alter during pregnancy, various clinical parameters should be closely monitored to modify dialysis settings accordingly. Of note, our case suggests that plasma atrial natriuretic peptide level is a useful parameter for the appropriate dry weight. Intensified hemodialysis is an effective and reliable measure that can achieve normal pregnancy in dialysis patients, even in a primigravida with advanced maternal age.
\end{abstract}

Keywords: Hemodialysis, Pregnancy, Dry weight, Atrial natriuretic peptide, Hypertension, Polyhydramnios, Fetal development

\section{Background}

In Japan, the total number of dialysis patients has increased exponentially, reaching 339,841 at the end of 2018 [1]. Notably, almost all of them (97.2\% in 2018) are on hemodialysis, a situation unique to Japan. Due to the shortage of kidneys for transplantation, even younger patients are obliged to be maintained by dialysis for a substantial period. Despite the increase of dialysis patients, however, most of these patients can survive and perform normal daily activities for a substantial period owing to the current advancement of dialysis technology.

Meanwhile, the rate of pregnancy at advanced maternal age (over 35 years) has been increasing among developed countries, including Japan, partly attributed to the increment of women's economic participation in the society [2]. In Japan, pregnancy in women over 35 years accounts for $28.3 \%$ of the total childbirth in 2015 [3]. However, pregnancy at advanced age is associated with increased risk of pregnancy complications and adverse perinatal outcomes, such as preterm birth, low birth weight, perinatal mortality, cesarean section, and maternal mortality $[2,4,5]$.

Pregnancy in dialysis patients is a rare clinical scenario and considered to be a significant maternal and fetal risk factor for the patient, thereby posing challenging clinical problems both for nephrologists and obstetricians [6, 7]. Common complications associated with this clinical setting include maternal hypertension, preeclampsia, polyhydramnios, intrauterine growth restriction and prematurity [8]. However, despite the risks and difficulties associated with pregnancy in dialysis patients, the literature and recommendations concerning this clinical context are scarce. Especially, only few previous reports discussing the reliable indicators of optimal dialysis prescription and body fluid management in pregnant patients, including plasma atrial natriuretic peptide (ANP) levels, are available [9], raising the importance of investigating each clinical case in detail. Besides, as previously described, pregnancy in dialysis patients with advanced age is an exceptionally rare and complicated clinical condition because of the increased risk of several complications associated with the increased maternal age and hemodialysis status.
Given the current situation stated above, herein, we describe a case of a primigravida with advanced age who had a history of multiple gynecologic disorders, undergoing a normal spontaneous vaginal delivery at full term under intensified hemodialysis since the first trimester.

\section{Case Presentation}

A 39-year-old gravida 2, para 0 woman with ESRD was referred to our department for hemodialysis management during pregnancy. She was diagnosed as IgA nephropathy at 21 years old, and reached ESRD in 2 years, initiating maintenance post-dilution hemodiafiltration. At 29 years old, according to her request, peritoneal dialysis was introduced in combination with hemodiafiltration, but discontinued in 4 years due to ultrafiltration failure. She was followed up as an outpatient with 4.5hour hemodiafiltration for thrice a week. She married at 34 years old and had a strong motive to have children. Although the risk of pregnancy in dialysis patients was high compared with pregnancy in normal patients, her risk of pregnancy was considered to be relatively low because she had been appropriately managed by maintenance hemodiafiltration without major complications. After extensive counselling regarding the risks and difficulties related to pregnancy, she initiated infertility treatments including in vitro fertilization and embryo transfer (IVF-ET). She had experienced cervical conization at 31 years old due to cervical dysplasia, laparoscopic right salpingo-oophorectomy at 36 years old due to right tubal ectopic pregnancy and spontaneous abortion at 38 years old. IVF-ET had been performed five times in total, in which the previous four attempts had failed. Seven months before referral, IVF-ET was reattempted. In addition, the hemodiafiltration schedule was altered from three times per week to four times per week, considering that the development of embryo sac was halted in the previous attempts of IVF-ET; normal hemodiafiltration prescription was still applied. At day 40 post-transfer, urine pregnancy test turned out to be positive, and obstetrics examinations confirmed that she was at 4 weeks of gestation. 
After pregnancy was confirmed, hemodiafiltration was switched to hemodialysis and the hemodialysis schedule was intensified to five times per week to achieve an appropriate control of serum urea nitrogen (UN) levels. At 10 weeks of gestation, the duration of hemodialysis was further increased, reaching a 6-hour hemodialysis for six times per week to achieve a weekly duration of 36 hours. As a result, weekly Kt/V and the hemodialysis product (HDP) were increased after the employment of intensified hemodialysis (Table 1). Throughout pregnancy, serum UN levels were persistently below $50 \mathrm{mg} /$ $\mathrm{dL}$. In addition to maternal blood pressure and fetal growth, post-dialysis plasma ANP levels were utilized as indicators of body fluid levels and maintained below 100 $\mathrm{pg} / \mathrm{mL}$; hence, her dry weight had been gradually incremented by 300-400 g/week (Fig. 1). During the first and second trimester, fetal development was normal. At 30 weeks and 2 days of gestation, she was admitted to the obstetrics department for perinatal management.

Upon admission, her examination was notable for conjunctival pallor and bilateral pitting edema in the lower extremities. She had an intact radiocephalic arteriovenous fistula on her right forearm, which was functional enough to support frequent hemodialysis. Estimated fetal weight was $1710 \mathrm{~g}:-1.0$ standard deviation (SD), and the amniotic fluid index (AFI) was $18.7 \mathrm{~cm}$. Her body height was $152.1 \mathrm{~cm}$, and her dry weight was adjusted to 60.4 $\mathrm{kg}$, which was $54.0 \mathrm{~kg}$ before pregnancy. Pre-dialysis laboratory data revealed the following laboratory results: white blood cell count, $6100 / \mu \mathrm{L}$; hemoglobin, $8.6 \mathrm{~g} / \mathrm{dL}$; hematocrit, 26.8\%; platelet count, $241000 / \mu \mathrm{L}$; albumin, $2.7 \mathrm{~g} / \mathrm{dL}$; total protein, $5.6 \mathrm{~g} / \mathrm{dL}$; creatinine, $5.39 \mathrm{mg} / \mathrm{dL}$; $\mathrm{UN}, 28 \mathrm{mg} / \mathrm{dL}$; aspartate transaminase, $17 \mathrm{U} / \mathrm{L}$; alanine transaminase, $14 \mathrm{U} / \mathrm{L}$; sodium, $139 \mathrm{mEq} / \mathrm{L}$; potassium, $4.3 \mathrm{mEq} / \mathrm{L}$; chloride, $100 \mathrm{mEq} / \mathrm{L}$; calcium, $9.2 \mathrm{mg} / \mathrm{dL}$; phosphate, $3.2 \mathrm{mg} / \mathrm{dL}$; and intact parathyroid hormone (iPTH), $502 \mathrm{pg} / \mathrm{mL}$.

Her past medical history was notable for polycystic ovarian syndrome, hypertension, and secondary hyperparathyroidism, for which parathyroidectomy with parathyroid auto-transplantation was conducted. Cinacalcet $50 \mathrm{mg}$ was administered for parathyroid remnant during outpatient visit but discontinued before IVF-ET, resulting in a high iPTH level during admission. Before pregnancy, she was on calcitriol $0.25 \mu \mathrm{g} / \mathrm{day}$, precipitated calcium carbonate $1000 \mathrm{mg} /$ day, and lanthanum carbonate hydrate $1500 \mathrm{mg} /$ day. After pregnancy was confirmed, these prescriptions were discontinued. She was on methyldopa at $125 \mathrm{mg}$ once a day for hypertension. Darbepoetin alfa $30 \mu \mathrm{g}$ was administered fortnightly before pregnancy. After pregnancy, its dosage was gradually increased and intravenous iron was initiated. Their dosages on admission were $120 \mu \mathrm{g} /$ week and $120 \mathrm{mg} /$ week, respectively. She was allergic to nifedipine, amlodipine and cefazolin. Meanwhile, her family history and social histories were unremarkable.

After admission, the outpatient hemodialysis schedule was continued. Throughout the third trimester, postdialysis plasma ANP levels were between 150 and 250 $\mathrm{pg} / \mathrm{mL}$, and her blood pressure was within 100-120 $\mathrm{mmHg}$ systolic and $60-80 \mathrm{mmHg}$ diastolic range without methyldopa. Her dry weight had been increased by $200 \mathrm{~g} /$ week, according to the fetal growth (Fig. 2). Fetal development and growth rate were within normal limits, and the estimated fetal weight was persistently within 1.5 standard deviations (Fig. 3). Placental blood flow and AFI were also within the referential range. Serum potassium levels, serum phosphate levels and acid-base status were closely monitored because hypokalemia, hypophosphatemia and metabolic alkalosis are common complications of the intensified hemodialysis. Serum potassium

Table 1 Summary of the dialysis prescription before and during pregnancy

\begin{tabular}{lll}
\hline & Before pregnancy & During pregnancy \\
\hline Dialysis modality & Hemodiafiltration (post-dilution) & Hemodialysis \\
Dialyzer & NV-21X polysulfone dialyzer (Toray medical) & APS-21SA polysulfone dialyzer (Asahi medical) \\
Dialysate & Kindaly 4E (FUSO Pharmaceutical) & Kindaly AF2 (FUSO Pharmaceutical) \\
Blood flow rate (mL/min) & 200 & 170 \\
Dialysate flow rate (mL/min) & 500 & 500 \\
Substitution flow rate (L/hour) & 2.7 & 0 \\
Frequency of dialysis (times/week) & 3 & 6 \\
Duration of dialysis (hours/session) & 4.5 & 6 \\
Dry weight (kg) & 54 & $62.7^{*}$ \\
Daily Kt $/$ (Daugirdas equation) & 1.76 & 1.55 \\
Weekly Kt $N$ & 2.47 & 5.51 \\
HDP & 40.5 & 216 \\
\hline
\end{tabular}

HDP, Hemodialysis product

*The day before delivery 


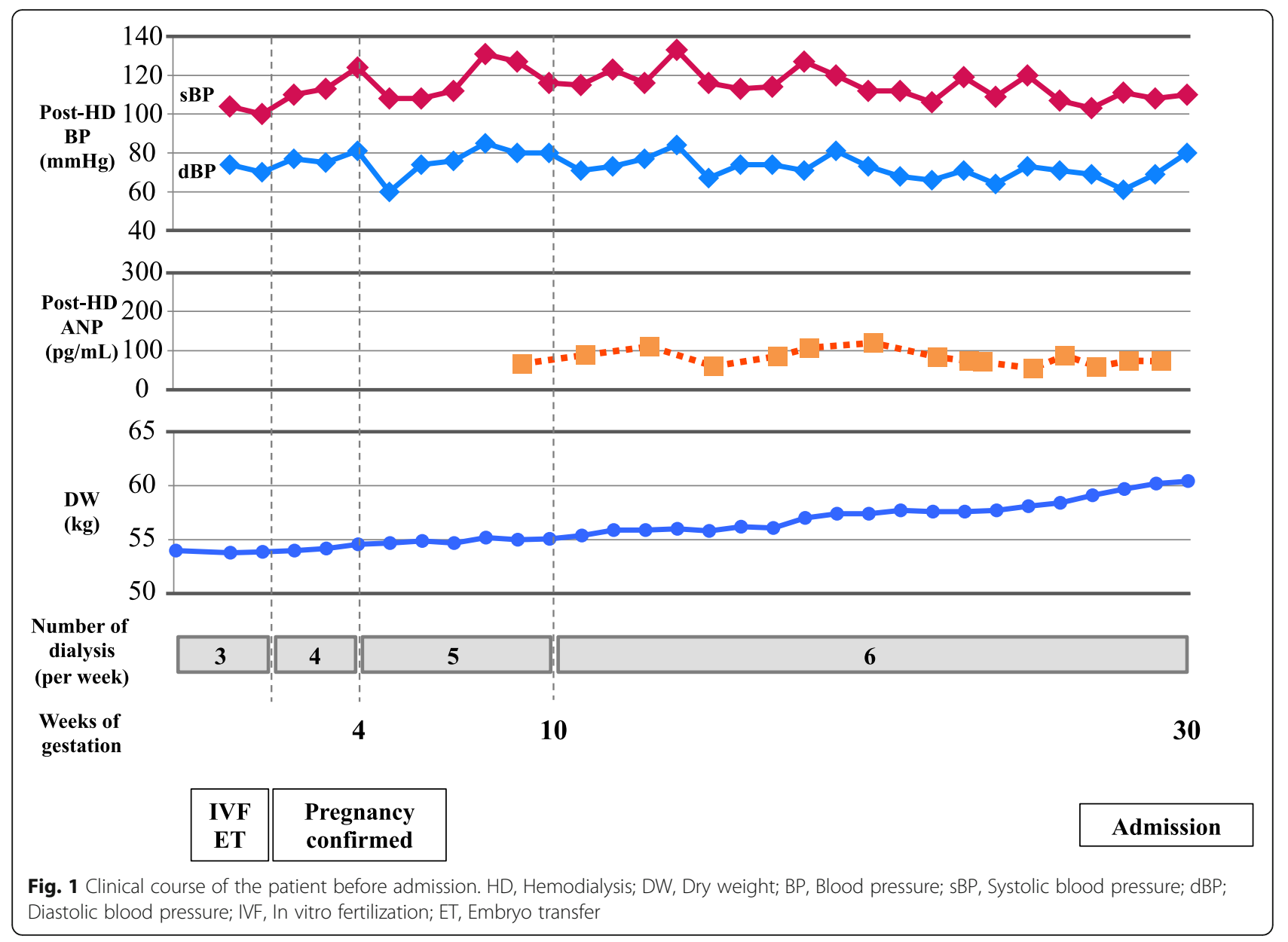

levels were maintained within the normal range owing to the reduction of dialysis efficiency and adequate dietary intake. Serum corrected calcium and phosphate levels were maintained at $9.9-10.8 \mathrm{mg} / \mathrm{dL}$ and $2.0-2.5 \mathrm{mg} /$ $\mathrm{dL}$, respectively. iPTH levels did not differ significantly from those during outpatient visit, stably maintained around 500 $\mathrm{pg} / \mathrm{mL}$. Dialysate calcium concentration during pregnancy was increased to $3.0 \mathrm{mEq} / \mathrm{L}(1.5 \mathrm{mmol} / \mathrm{L})$, while that before pregnancy was $2.75 \mathrm{mEq} / \mathrm{L}(1.375 \mathrm{mmol} / \mathrm{L})$. Metabolic alkalosis was also prevented by closely following acid-base status and decreasing dialysate bicarbonate concentration accordingly (data not shown). Hemoglobin levels were controlled between 10 and $12 \mathrm{~g} / \mathrm{dL}$ during the third trimester without further increment of darbepoetin alfa and intravenous iron after admission. Despite the longer duration of hemodialysis, her mental status was in good condition, and her vascular access was intact throughout the pregnancy period. After thorough patient counseling and discussion with obstetricians, vaginal delivery under close surveillance was adopted.

At 38 weeks and 3 days of gestation, she gave birth to a healthy female child through a normal spontaneous vaginal delivery at full term. Hemodialysis was continued until the day before childbirth. The baby weighed $2490 \mathrm{~g}$ : -1.0 SD, with an Apgar score of 8/9. The placental weight was $596 \mathrm{~g}$, and the amount of intrapartum bleeding including amniotic fluid was $1084 \mathrm{~mL}$. Considering that maternal health status remained to be in good condition after delivery, maintenance hemodialysis was resumed at day 1 postpartum. Her pre-dialysis body weight at day 1 postpartum was $57.9 \mathrm{~kg}$; hence, $4.8 \mathrm{~kg}$ was reduced from her prepartum body weight. Her blood pressure was approximately $120 / 80 \mathrm{mmHg}$, and the cardiothoracic ratio at day 1 postpartum was $42.7 \%$, which was comparable with that measured before pregnancy. Based on these findings, her dry weight was readjusted to $57.0 \mathrm{~kg}$. Hemodialysis was performed 3 days in a row, from day 1 to day 3 postpartum, without complications including postpartum hemorrhage under dalteparin use. At day 5 postpartum, she was discharged with her child and followed up as an outpatient with a 5-hour hemodialysis for thrice a week. After admission, calcitriol $0.25 \mu \mathrm{g}$ and bixalomer $1500 \mathrm{mg}$ were initiated for secondary hyperparathyroidism and serum iPTH levels were maintained within the referential range. To date, her child's development has been normal, both mentally and physically. 


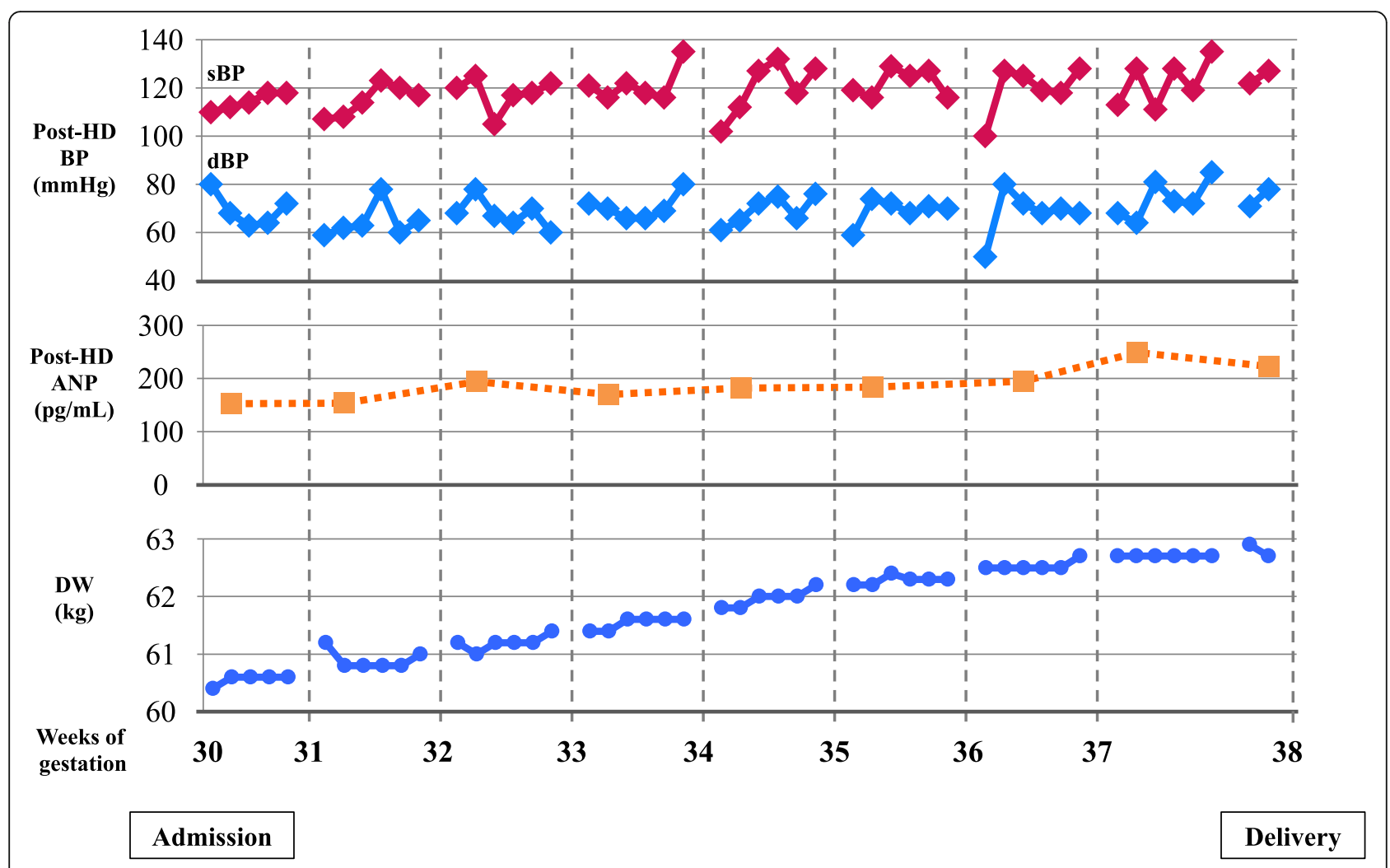

Fig. 2 Clinical course of the patient after admission. HD, Hemodialysis; DW, Dry weight; BP, Blood pressure; sBP, Systolic blood pressure; dBP; Diastolic blood pressure

\section{Discussion}

Our patient was a primigravida with advanced age who delivered a healthy female child at full term without major maternal and fetal complications, although she had a history of several gynecologic disorders. To the best of our knowledge, our case is the hemodialysis patient with the most advanced age who successfully delivers vaginally at full term without complications.

To prevent volume overload and the accumulation of hyperosmotic substances (e.g. UN), which increase the

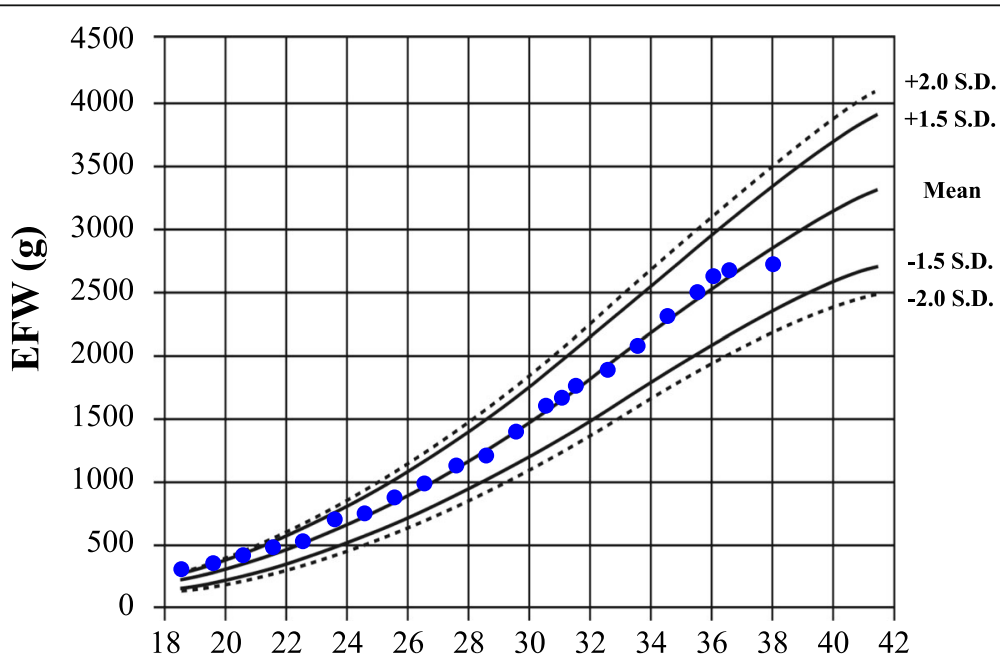

Weeks of gestation

Fig. 3 Estimated fetal weight. EFW, Estimated fetal weight 
risk of maternal hypertension and polyhydramnios, the frequency and duration of hemodialysis were increased stepwise, and a weekly hemodialysis duration of 36 hours was achieved at 10 weeks of gestation. Applying intensified hemodialysis in pregnancy is proven effective in achieving favorable maternal and fetal outcomes [10-12]. In a comparative analysis of Canadian and American cohorts, women dialyzed more than 36 hours per week revealed higher live birth rates than those dialyzed less than 20 hours per week ( $85 \%$ vs $48 \%$ ), with a longer gestational age and greater infant birth weight [13]. In our case, serum UN levels were maintained within $40 \mathrm{mg} / \mathrm{dL}$ and $50 \mathrm{mg} /$ dL throughout pregnancy by intensified hemodialysis, without any signs of fetal growth restriction or polyhydramnios. As shown in Table 1, although Kt/V per each dialysis session was decreased, weekly $\mathrm{Kt} / \mathrm{V}$ after pregnancy was rather increased owing to the increase of dialysis frequency. To avoid rapid changes in serum osmolarity, frequent hemodialysis with smaller $\mathrm{Kt} / \mathrm{V}$ per each dialysis session might be advantageous. Likewise, the HDP was remarkably increased from 40.5 before pregnancy to 216 after the employment of intensified hemodialysis. It is suggested that the higher HDP correlates with more favorable clinical outcomes [14]; therefore, the intensified hemodialysis schedule presumably contributed to favorable maternal and fetal outcomes in our case. Besides, although the previous attempts of IVF-ET had failed under normal hemodialysis schedule, early application of the intensified hemodialysis immediately after the last IVF-ET might contribute to the successful conception. Although common complications associated with the intensified hemodialysis include hypokalemia, hypophosphatemia, metabolic alkalosis, impaired vascular access and maternal depression, the complications hypokalemia and hypophosphatemia were not observed owing to the reduction of dialysis efficiency per each dialysis session and adequate dietary intake. In order to meet maternal and fetal demand for calcium, dialysate calcium concentration was increased after pregnancy and serum corrected calcium levels were maintained over $9.9 \mathrm{mg} / \mathrm{dL}$. Metabolic alkalosis was prevented by decreasing dialysate bicarbonate concentration and her acid-base status was properly controlled throughout pregnancy. Her vascular access remained intact and her mental status was in good condition, both during and after pregnancy.

Regarding maternal volume status, we utilized several clinical parameters as indicators of the appropriate maternal dry weight, including maternal blood pressure, post-dialysis plasma ANP, chest X-ray, placental blood flow and fetal development. We gradually increased the maternal dry weight by $300-400 \mathrm{~g} /$ week in the first and second trimester. In the third trimester, however, we tapered down the increment of the maternal dry weight by approximately $200 \mathrm{~g} /$ week, because the rate of fetal weight gain had relatively slowed down, compared with the earlier stages of pregnancy (Fig. 3). Complications related to maternal volume overload, such as maternal hypertension or polyhydramnios, were not observed.

Concerning plasma ANP levels, although they were maintained approximately $70-80 \mathrm{pg} / \mathrm{mL}$ in the first and second trimester, they had gradually increased to 150 $250 \mathrm{pg} / \mathrm{mL}$ in the third trimester (Fig. 1 and Fig. 2). Despite the elevation of plasma ANP levels, other clinical parameters such as maternal blood pressure, chest $\mathrm{X}$ ray, amniotic fluid index, placental blood flow and fetal development were within normal limits, suggesting that the maternal body fluid status was not hypervolemic. Taken together, although no single factor is a sole determinant of ideal dry weight, controlling plasma ANP levels below $100 \mathrm{pg} / \mathrm{mL}$ in the early stages of pregnancy and increasing the target plasma ANP level to 150-250 $\mathrm{pg} / \mathrm{mL}$ in the third trimester would be reasonable to accomplish adequate volume control in pregnant patients receiving dialysis, given that the normal range of plasma ANP levels is elevated during pregnancy [15-17] and hemodynamic instability due to excessive fluid removal can cause adverse effects on fetal growth and development. In Japan, post-dialysis plasma ANP levels are frequently monitored in hemodialysis centers; therefore, utilizing plasma ANP levels as indicators of maternal volume status would be a practical strategy. The pathophysiology of ANP during pregnancy will be discussed comprehensively in mini-review.

With respect to the management of renal anemia, although the patient was slightly anemic on admission, her hemoglobin levels were maintained from $10 \mathrm{~g} / \mathrm{dL}$ to $12 \mathrm{~g} / \mathrm{dL}$ in the third trimester under darbepoetin alfa and intravenous iron. Anemia during pregnancy is associated with increased incidence of preterm birth and lower birth weight [18]; therefore, appropriate control of hemoglobin levels might be one of the contributing factors to the favorable fetal outcomes.

Overall, through the proper control of body fluid levels and the adequate solute removal by the intensified hemodialysis, normal fetal development and childbirth at full term were accomplished without complications. The case of pregnancy in dialysis patients with advanced age that results in a full-term vaginal delivery without complications is exceptionally rare.

\section{Mini-review of hemodialysis management in pregnant patients \\ Epidemiology and associated risks of pregnancy in dialysis patients}

The incidence of pregnancy in women on long-term hemodialysis ranges from $<1 \%$ to approximately $7 \%$ [19], although results are varied among different studies, probably because of the heterogeneity of study populations and 
statistical biases. The average gestational age of delivery in pregnant patients undergoing dialysis was 33.8 weeks, and the median birth weight was $1750 \mathrm{~g}$ [10]. Pregnancy rate is higher among patients on hemodialysis than that among patients on peritoneal dialysis [20-22]. One explanation is that hemodialysis facilitates more adequate solute removal and volume control than peritoneal dialysis, exemplifying the importance of intensified hemodialysis prescription during pregnancy. Despite the difficulties and complications discussed, live birth percentage of pregnancy in dialysis patients has increased, reaching from $20-23 \%$ in 1980 s to approximately $75 \%$, partly due to the improved medical management $[8,20,21]$. A meta-regression analysis revealed that the number of reported cases of pregnancy in patients undergoing dialysis had increased rapidly, especially since 2000 [20].

Despite these findings, however, the risk of pregnancy in dialysis patients is still considered to be high, posing challenging problems for nephrologists and obstetricians. Pregnancy in dialysis patients has long been considered to be a significant risk factor for mothers and fetuses because of the associated complications, including maternal hypertension, preeclampsia, polyhydramnios, preterm birth and intrauterine fetal growth restriction $[8$, 19, 23]. Furthermore, the frequency of irregular menstrual cycle and sexual dysfunction in these patients is high because of various endocrine abnormalities related to impaired renal function, affecting the conception rate [24]. A previous report revealed that hypertension existed in $79 \%$ of pregnant patients undergoing hemodialysis, and 32\% of them had blood pressure over 170/110 $\mathrm{mmHg}$ [21]. Given that maternal hypertension and preeclampsia are major risk factors for prematurity, maternal blood pressure and body fluid levels should be crucially monitored. In addition, polyhydramnios is induced by an increased maternal volume status, which enhances placental blood flow and fetal circulating blood volume, resulting in increased fetal urine output and amniotic fluid volume [25, 26]. Polyhydramnios can also develop due to maternal azotemia and alteration of plasma osmotic pressure during dialysis.

\section{Hemodialysis management during pregnancy}

Although several reports about pregnancy in hemodialysis patients exist, most of them are mere case reports or small-scale cohort studies, and no randomized trial regarding this clinical context has been conducted. Recently, the Italian Society of Nephrology and the Japanese Society of Nephrology independently published guidelines for pregnancy in patients with chronic kidney diseases [27, 28], and recommendations for hemodialysis management during pregnancy are mentioned on the basis of previous studies, as summarized in Table 2 [11, 12, 29-39].

Regarding the frequency and duration of hemodialysis, previous guidelines recommend that hemodialysis should be performed at least four times per week to secure a hemodialysis duration of 20 hours per week and keep serum UN levels below $50 \mathrm{mg} / \mathrm{dL}$ [27, 28]. In addition, they also suggested that securing a hemodialysis duration of 24 hours per week and a hemodialysis frequency of six times per week is highly advantageous. Indeed, intensified hemodialysis in pregnancy appears to be effective in achieving favorable maternal and fetal outcomes. As shown in Table 2, the frequency and duration of hemodialysis in most studies are increased during pregnancy. A publication from Germany suggests that by extending the hemodialysis duration longer than 24 hours per week, $100 \%$ of live birth rate can be accomplished [12]. Another report from Canada indicates that nocturnal home dialysis with an average hemodialysis duration of 48 hours per week results in longer gestation and increased birth weight with an improved live birth rate [31]. Pre-dialysis serum UN levels are negatively correlated with gestational age and birth weight, and keeping serum UN levels below $48 \mathrm{mg} / \mathrm{dL}$ corresponds to a gestational age of more than 32 weeks [11]. It is suggested to be advantageous to maintain serum UN levels within $16 \mathrm{mmol} / \mathrm{L}(44.8 \mathrm{mg} / \mathrm{dL})$ and $18 \mathrm{mmol} / \mathrm{L}(50.4 \mathrm{mg} /$ dL) $[8,25]$. Overall, although the exact hemodialysis dose differs among studies, intensified hemodialysis contributes to improved prenatal outcomes. However, it should be noted that although a weekly hemodialysis duration of 20 hours is recommended in the guidelines, these recommendations mainly focus on European and Japanese patients; therefore, a more intensified hemodialysis schedule might be appropriate for another population according to their eating habits or body habitus. Indeed, as mentioned previously, Canadian and American cohorts dialyzed more than 36 hours per week had favorable maternal and fetal outcomes compared with those dialyzed less than 20 hours per week [13].

\section{Assessment of body fluid status during pregnancy}

The ideal dry weight during pregnancy is difficult to ascertain, owing to the change of gestational fetal weight gain and maternal nutritional status from physiological conditions. Maternal blood pressure is an important factor to determine the dry weight, but dialysis-induced hypotension and hemodynamic instability can reduce uteroplacental circulation, causing adverse effects on fetal growth. To prevent excessive fluid removal, we should employ a consistent hemodialysis schedule to reduce interdialytic weight gain. A minimal weight gain of $1.0-1.5 \mathrm{~kg}$ is expected to occur in the first trimester, whereas the rate of weight gain amounts to approximately $0.45 \mathrm{~kg} /$ week after the first trimester [26]. Based on these findings, increasing the maternal dry weight by $200 \mathrm{~g} /$ week in the first trimester and 300-400 g/week afterwards would be reasonable while closely monitoring the maternal blood pressure. Previous guidelines recommend 


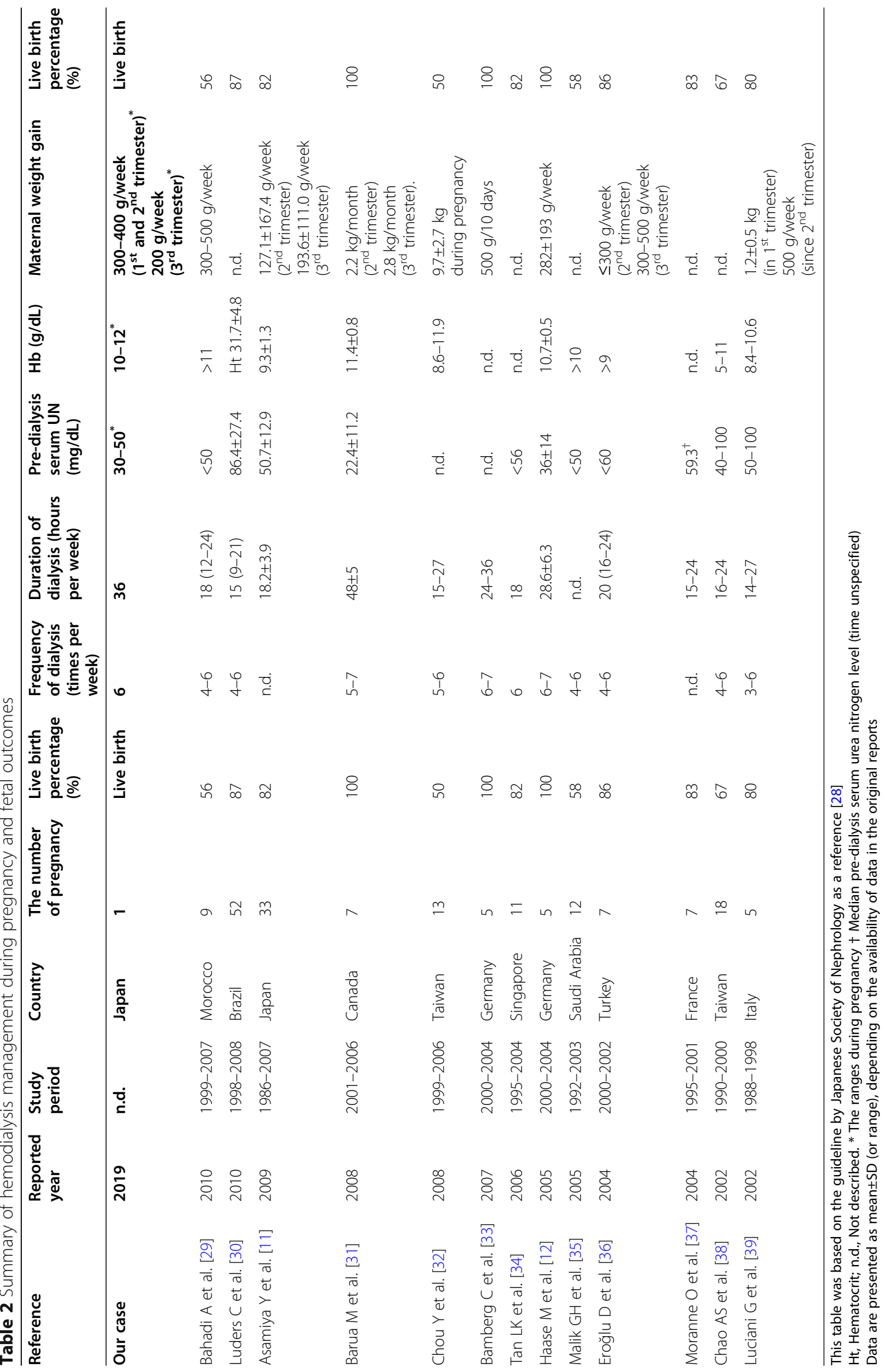


that dry weight should be increased by $300-500$ g per week in the second and third trimester, while closely monitoring the body fluid status [27, 28]. In some cases, dry weight is increased by 300-500 g/week, as recommended in the guidelines (Table 2); however, a wide variation in weight gain exists among different studies.

Post-dialysis plasma ANP level is also a good indicator to speculate the volume status in pregnant patients, as well as in patients receiving normal hemodialysis. Although previous reports are scarce, regular monitoring of plasma ANP levels could contribute to an appropriate maternal volume control in pregnant patients $[9,40]$. Of note, the normal range of plasma ANP levels during pregnancy might differ from the physiological condition. Although still controversial, previous reports indicate that plasma ANP levels in normal pregnant patients are slightly elevated compared with postpartum (25-100\% increase from baseline); this elevation is attributed to pregnancy-related physiological changes, such as hypervolemia, high cardiac output and decreased vascular resistance [15-17]. In addition, the pro-atrial natriuretic peptide convertase corin, which is a cardiac protease that activates ANP, is highly expressed in pregnant uterus and essential for trophoblast invasion and spiral artery remodelling [41, 42]. Corin and ANP contribute to the hemodynamic change and placental development during pregnancy, but uterine corin expression is impaired in patients with preeclampsia. Therefore, the interaction of corin and ANP might partly explain the elevated plasma ANP levels during pregnancy.

However, it should be noted that the normal range of plasma ANP levels in dialysis patients during pregnancy has yet to be elucidated in the previous literature; therefore, further studies are needed to establish the normal range of plasma ANP levels and utilize them as determinant of appropriate dry weight in dialysis patients during pregnancy.

\section{Management of renal anemia during pregnancy}

Although the target hemoglobin level is considerably varied (Table 2), controlling the hemoglobin levels from $10 \mathrm{~g} / \mathrm{dL}$ to $11 \mathrm{~g} / \mathrm{dL}$ would be reasonable, given that a high hemoglobin level positively correlates with live birth rate [11]. Required erythropoietin dosages increase by $50-100 \%$ to maintain appropriate hemoglobin levels compared with the baseline $[8,43]$. The underlying mechanism for the increased erythropoietin requirement during pregnancy involves multiple factors, including an increased demand for supporting placental blood flow and fetal development, the loss of blood and iron due to the intensified hemodialysis, and erythropoietin resistance presumably due to increased cytokine production during pregnancy [19].
Intravenous iron is considered to be a safe and effective measure to improve hemoglobin levels, even in pregnancy [44]. Although studies investigating the exact target hemoglobin levels during pregnancy are relatively scarce (Table 2), previous guidelines recommend to control hemoglobin levels from $10 \mathrm{~g} / \mathrm{dL}$ to $11 \mathrm{~g} / \mathrm{dL}$ [27, 28]. Hemoglobin levels should be closely monitored, and the dosages of intravenous erythropoietin and iron should be adjusted accordingly.

\section{Management of CKD-MBD during pregnancy}

Target values of serum calcium, phosphate, and iPTH levels in pregnant patients receiving dialysis are considered same as those in non-pregnant patients [8]. As mentioned previously, hypophosphatemia is one of the most common complications related to intensified hemodialysis. In order to prevent hypophosphatemia, increased dietary intake or oral phosphate supplements could be effective. One report also suggests that the increase of dialysate phosphate concentration by adding sodium phosphate salts could prevent severe hypophosphatemia under intensified hemodialysis during pregnancy [45]. In order to facilitate fetal skeletal development, adequate maternal intake of calcium during pregnancy is also important. Some reports recommend to maintain the dialysate calcium concentration more than 3.0 $\mathrm{mEq} / \mathrm{L}(1.5 \mathrm{mmol} / \mathrm{L})$ to meet fetal and maternal demand for calcium $[8,31]$. Human placentas have the ability to convert calcidiol into calcitriol [46], but the clinical consequence caused by placental production of calcitriol is still unclear. Overall, close monitoring of laboratory data is necessary to control CKD-MBD in dialysis patients during pregnancy.

\section{Conclusion}

The number of pregnancies in hemodialysis patients with advanced age is expected to further increase in the near future; therefore, establishing a reliable clinical strategy for the management of these patients is crucial. We suggest that intensified hemodialysis is an effective and reliable measure to achieve normal pregnancy in hemodialysis patients, even in a primigravida with advance maternal age. Intensified hemodialysis can contribute not only to a higher live birth rate but also to the favorable pregnancy outcomes, including full-term delivery.

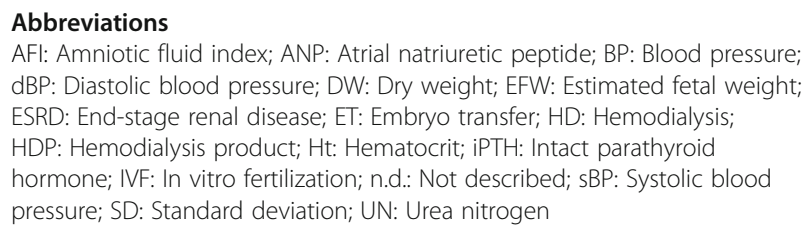

\section{Acknowledgements}

We thank dialysis staffs at Ikeda clinic and Kyoto University Hospital for providing invaluable technical assistance and dedicated patient care. 


\section{Authors' contributions}

$\mathrm{HA}$, KPM, and HY wrote the manuscript. KM, JO, KS, TE, YI, TM, TT, and MY contributed to the treatment of patients and discussion, and reviewed the manuscript. All authors read and approved the final version of the manuscript.

\section{Funding}

This study was not supported by any funding.

\section{Availability of data and materials \\ Not applicable.}

\section{Ethics approval and consent to participate}

Not applicable.

\section{Consent for publication}

Written informed consent was obtained from the patient for the publication of this case report and any accompanying images. Proof of consent to publish from the patient can be requested by the editors and/or reviewer at any time.

\section{Competing interests}

The corresponding author is serving as an associate editor in Renal Replacement Therapy.

\section{Author details}

'Department of Nephrology, Graduate School of Medicine, Kyoto University, 54 Shogoin Kawahara-cho, Sakyo-ku, Kyoto 606-8507, Japan. ${ }^{2}$ TMK Project, Medical Innovation Center, Graduate School of Medicine, Kyoto University, 53 Shogoin Kawahara-cho, Sakyo-ku, Kyoto 606-8507, Japan. ${ }^{3}$ Institute for the Advanced Study of Human Biology (ASHBi), Kyoto University, Yoshida-Konoe-cho, Sakyo-ku, Kyoto 606-8501, Japan. ${ }^{4}$ Department of Gynecology and Obstetrics, Saiseikai-Noe Hospital, 1-3-25 Furuichi, Joto-ku, Osaka 536-0001, Japan. ${ }^{5}$ Department of Gynecology and Obstetrics, Graduate School of Medicine, Kyoto University, 54 Shogoin Kawahara-cho, Sakyo-ku, Kyoto 606-8507, Japan. ${ }^{6}$ Department of Gynecology and Obstetrics, Mitsubishi Kyoto Hospital, 1 Katsuragosho-cho, Nishikyo-ku, Kyoto 615-8087, Japan. ${ }^{7}$ Department of Nephrology and Dialysis, Tazuke Kofukai Medical Research Institute, Kitano Hospital, 2-4-20 Ohgimachi, Kita-ku, Osaka 530-8480, Japan. ${ }^{8}$ Ikeda Clinic, 579 Kakimoto-cho, Gojyo-Horikawa-Nishiiru, Shimogyo-ku, Kyoto 600-8357, Japan.

\section{Received: 23 March 2020 Accepted: 7 October 2020}

Published online: 27 October 2020

\section{References}

1. Nitta K, Masakane I, Hanafusa N, Goto S, Abe M, Nakai S, et al. 2018 Annual Dialysis Data Report, JSDT Renal Data Registry. Tousekikaishi. 2019:52(12): 679-754.

2. Ogawa K, Urayama KY, Tanigaki S, Sago H, Sato S, Saito S, et al. Association between very advanced maternal age and adverse pregnancy outcomes: a cross sectional Japanese study. BMC Pregnancy Childbirth. 2017;17(1):349.

3. Ministry of Health Labour and Welfare. Live births and live birth rates (per 1,000 female population) by the age of mothers (5-year age group); mean age of mothers and age-standardized live birth rates (per 1,000 female population), by live birth order and occupation of mother (major groups) [Available from: https://www.e-stat.go.jp/en

4. Jacobsson B, Ladfors L, Milsom I. Advanced maternal age and adverse perinatal outcome. Obstet Gynecol. 2004;104(4):727-33.

5. Jolly M, Sebire N, Harris J, Robinson S, Regan L. The risks associated with pregnancy in women aged 35 years or older. Hum Reprod. 2000;15(11):2433-7.

6. Jungers P, Chauveau D. Pregnancy in renal disease. Kidney Int. 1997: 52(4):871-85.

7. Piccoli GB, Conijn A, Consiglio V, Vasario E, Attini R, Deagostini MC, et al. Pregnancy in dialysis patients: is the evidence strong enough to lead us to change our counseling policy? Clinical journal of the American Society of Nephrology : CJASN. 2010;5(1):62-71.

8. Manisco G, Poti M, Maggiulli G, Di Tullio M, Losappio V, Vernaglione L. Pregnancy in end-stage renal disease patients on dialysis: how to achieve a successful delivery. Clin Kidney J. 2015;8(3):293-9.
9. Matsuo N, Nakayama Y, Inoue H, Izumi Y, Mukoyama M. Successful full-term delivery in a patient with maintenance hemodialysis using natriuretic peptides as volume markers without $\mathrm{X}$-ray examination: a case report and literature review. Renal Replacement Therapy. 2019;5(1):32.

10. Jesudason S, Grace BS, McDonald SP. Pregnancy outcomes according to dialysis commencing before or after conception in women with ESRD. Clinical journal of the American Society of Nephrology: CJASN. 2014;9(1):143-9.

11. Asamiya Y, Otsubo S, Matsuda Y, Kimata N, Kikuchi KAN, Miwa N, et al. The importance of low blood urea nitrogen levels in pregnant patients undergoing hemodialysis to optimize birth weight and gestational age. Kidney Int. 2009;75(11):1217-22.

12. Haase M, Morgera S, Bamberg C, Halle H, Martini S, Hocher B, et al. A systematic approach to managing pregnant dialysis patients--the importance of an intensified haemodiafiltration protocol. Nephrology, dialysis, transplantation : official publication of the European Dialysis and Transplant Association - European Renal Association. 2005;20(11):2537-42.

13. Hladunewich MA, Hou S, Odutayo A, Cornelis T, Pierratos A, Goldstein M, et al. Intensive hemodialysis associates with improved pregnancy outcomes: a Canadian and United States cohort comparison. Journal of the American Society of Nephrology : JASN. 2014;25(5):1103-9.

14. Scribner BH, Oreopoulos DG. The Hemodialysis Product (HDP): A better index of dialysis adequacy than Kt/N. Dialysis \& Transplantation. 2011; 40(10):431-3.

15. Castro LC, Hobel CJ, Gornbein J. Plasma levels of atrial natriuretic peptide in normal and hypertensive pregnancies: a meta-analysis. Am J Obstet Gynecol. 1994;171(6):1642-51.

16. Sala C, Campise M, Ambroso G, Motta T, Zanchetti A, Morganti A. Atrial natriuretic peptide and hemodynamic changes during normal human pregnancy. Hypertension. 1995;25(4 Pt 1):631-6.

17. Chapman AB, Abraham WT, Zamudio S, Coffin C, Merouani A, Young D, et al. Temporal relationships between hormonal and hemodynamic changes in early human pregnancy. Kidney Int. 1998;54(6):2056-63.

18. Levy A, Fraser D, Katz M, Mazor M, Sheiner E. Maternal anemia during pregnancy is an independent risk factor for low birthweight and preterm delivery. Eur J Obstet Gynecol Reprod Biol. 2005;122(2):182-6.

19. Hladunewich M, Hercz AE, Keunen J, Chan C, Pierratos A. Pregnancy in end stage renal disease. Semin Dial. 2011;24(6):634-9.

20. Piccoli GB, Minelli F, Versino E, Cabiddu G, Attini R, Vigotti FN, et al. Pregnancy in dialysis patients in the new millennium: a systematic review and meta-regression analysis correlating dialysis schedules and pregnancy outcomes. Nephrology, dialysis, transplantation : official publication of the European Dialysis and Transplant Association - European Renal Association. 2016:31(11):1915-34

21. Okundaye I, Abrinko P, Hou S. Registry of pregnancy in dialysis patients. Am Jidney Dis. 1998;31(5):766-73.

22. Shahir AK, Briggs N, Katsoulis J, Levidiotis V. An observational outcomes study from 1966-2008, examining pregnancy and neonatal outcomes from dialysed women using data from the ANZDATA Registry. Nephrology (Carlton). 2013:18(4):276-84.

23. Bagon JA, Vernaeve H, De Muylder X, Lafontaine JJ, Martens J, Van Roost G. Pregnancy and dialysis. Am J Kidney Dis. 1998;31(5):756-65.

24. Holley JL, Schmidt RJ, Bender FH, Dumler F, Schiff M. Gynecologic and reproductive issues in women on dialysis. Am J Kidney Dis. 1997;29(5):685-90.

25. Kubo K. Pregnancy and delivery in dialysis patients. Tousekikaishi. 2003;36: 1413-21.

26. Giatras I, Levy DP, Malone FD, Carlson JA, Jungers P. Pregnancy during dialysis: case report and management guidelines. Nephrology, dialysis, transplantation : official publication of the European Dialysis and Transplant Association - European Renal Association. 1998:13(12):3266-72.

27. Cabiddu G, Castellino S, Gernone G, Santoro D, Giacchino F, Credendino O, et al. Best practices on pregnancy on dialysis: the Italian Study Group on Kidney and Pregnancy. J Nephrol. 2015;28(3):279-88.

28. Japanese Society of Nephrology. Clinical practice guidelines for the management of pregnancy in kidney disease patients in 2017 Accessed 17 June 2019 [Available from: http://cdn.jsn.or.jp/data/jsn-pregnancy.pdf.

29. Bahadi A, El Kabbaj D, Guelzim K, Kouach J, Hassani M, Maoujoud O, et al. Pregnancy during hemodialysis: a single center experience. Saudi J Kidney Dis Transpl. 2010;21(4):646-51.

30. Luders C, Castro MCM, Titan SM, De Castro I, Elias RM, Abensur H, et al. Obstetric outcome in pregnant women on long-term dialysis: a case series. Am J Kidney Dis. 2010;56(1):77-85. 
31. Barua M, Hladunewich M, Keunen J, Pierratos A, McFarlane P, Sood M, et al. Successful pregnancies on nocturnal home hemodialysis. Clinical journal of the American Society of Nephrology : CJASN. 2008;3(2):392-6.

32. Chou C-Y, Ting IW, Lin T-H, Lee C-N. Pregnancy in patients on chronic dialysis: a single center experience and combined analysis of reported results. Eur J Obstet Gynecol Reprod Biol. 2008;136(2):165-70

33. Bamberg C, Diekmann F, Haase M, Budde K, Hocher B, Halle H, et al. Pregnancy on intensified hemodialysis: fetal surveillance and perinatal outcome. Fetal Diagn Ther. 2007;22(4):289-93.

34. Tan LK, Kanagalingam D, Tan HK, Choong HL. Obstetric outcomes in women with end-stage renal failure requiring renal dialysis. Int I Gynaecol Obstet. 2006;94(1):17-22.

35. Malik GH, Al-Harbi A, Al-Mohaya S, Dohaimi H, Kechrid M, Shetaia MS, et al. Pregnancy in patients on dialysis--experience at a referral center. J Assoc Physicians India. 2005;53:937-41.

36. Eroğlu D, Lembet A, Ozdemir FN, Ergin T, Kazanci F, Kuşcu E, et al. Pregnancy during hemodialysis: perinatal outcome in our cases. Transplant Proc. 2004;36(1):53-5.

37. Moranne O, Samouelian V, Lapeyre F, Pagniez D, Subtil D, Dequiedt $P$, et al. Pregnancy and hemodialysis. Nephrologie. 2004;25(7):287-92.

38. Chao A-S, Huang J-Y, Lien R, Kung F-T, Chen P-J, Hsieh PCC. Pregnancy in women who undergo long-term hemodialysis. Am J Obstet Gynecol. 2002; 187(1):152-6.

39. Luciani G, Bossola M, Tazza L, Panocchia N, Liberatori M, De Carolis S, et al. Pregnancy during chronic hemodialysis: a single dialysis-unit experience with five cases. Ren Fail. 2002;24(6):853-62.

40. Horiguchi T, Ishikawa I, Takada K, Nakamura M, Tateishi K, Ishii H, et al. Successful pregnancy and delivery in two patients on maintenance hemodialysis-usefulness of a-human atrial natriuretic peptide in determining dry weight. Tousekikaishi. 1993;26:1225-30.

41. Chan JCY, Knudson O, Wu F, Morser J, Dole WP, Wu Q. Hypertension in mice lacking the proatrial natriuretic peptide convertase corin. Proc Natl Acad Sci U S A. 2005;102(3):785-90

42. Cui Y, Wang W, Dong N, Lou J, Srinivasan DK, Cheng W, et al. Role of corin in trophoblast invasion and uterine spiral artery remodelling in pregnancy. Nature. 2012;484(7393):246-50.

43. Reddy SS, Holley JL. The importance of increased dialysis and anemia management for infant survival in pregnant women on hemodialysis. Kidney Int. 2009;75(11):1133-4.

44. Reddy SS, Holley JL. Management of the pregnant chronic dialysis patient. Adv Chronic Kidney Dis. 2007;14(2):146-55.

45. Hussain S, Savin V, Piering W, Tomasi J, Blumenthal S. Phosphorus-enriched hemodialysis during pregnancy: Two case reports. Hemodial Int. 2005;9(2): $147-52$.

46. Díaz L, Sánchez I, Avila E, Halhali A, Vilchis F, Larrea F. Identification of a 25hydroxyvitamin D3 1alpha-hydroxylase gene transcription product in cultures of human syncytiotrophoblast cells. J Clin Endocrinol Metab. 2000; 85(7):2543-9.

\section{Publisher's Note}

Springer Nature remains neutral with regard to jurisdictional claims in published maps and institutional affiliations.

Ready to submit your research? Choose BMC and benefit from:

- fast, convenient online submission

- thorough peer review by experienced researchers in your field

- rapid publication on acceptance

- support for research data, including large and complex data types

- gold Open Access which fosters wider collaboration and increased citations

- maximum visibility for your research: over $100 \mathrm{M}$ website views per year

At $\mathrm{BMC}$, research is always in progress.

Learn more biomedcentral.com/submissions 